\title{
Post-drilling recrystallization of the Byrd Station deep ice core and its relevance to current and future deep-core drilling on polar ice sheets
}

\author{
A. J. Gow \\ U.S. Army Cold Regions Research and Engineering Laboratory, Hanover, NH 03755, U.S.A.
}

\begin{abstract}
Cores of highly strained ice recovered from depths of $1200-1800 \mathrm{~m}$ at Byrd Station in 1967-68 have been found to have recrystallized while in storage in the United States. Such recrystallization, inferred to have occurred when temperatures in the storage facility rose above about $-14^{\circ} \mathrm{C}$, would not have been discovered if thin sections of the cores had not been prepared and photographed at the drill site within hours of pulling the cores to the surface. It was only after new sections of the longstored cores were compared with the original sections that the full extent of recrystallization was revealed. The recrystallized structure emulates in both texture and fabric those observed in naturally annealed ice in the bottom $350 \mathrm{~m}$ at Byrd Station. It is concluded that polar ice cores should be stored at temperatures of $-20^{\circ} \mathrm{C}$ or colder in order to inhibit or minimize post-drilling recrystallization.
\end{abstract}

\section{INTRODUCTION}

Crystal structure and $c$-axis fabric measurements of vertically drilled cores constitute the primary source of information for interpreting the strain history of an icc shect. Accordingly, the textures and fabrics of ice cores must be monitored at regular intervals during drilling to assess changes occurring in these two important structural parameters. Knowledge of structure at the polycrystalline level and its changes with depth is also important in the modeling of depth-age relationships in the ice and in the reconstruction of paleoclimate records.

A case in point is the Byrd Station 1967-68 deep ice core from which large numbers of thin sections were prepared and photographed as soon as cores were brought to the surface. These sections, together with short pieces of core from which they were prepared, were returned in 1968 to CRREL where they have been stored at $-30^{\circ}$ to $-35^{\circ} \mathrm{C}$ during the intervening 25 years. Pcriodic re-examinations of these original thin sections from Byrd Station 10, 16 and 25 years after the cores were drilled, together with observations in 1990 and 1993 of new sections of the $10 \mathrm{~cm}$ long parent samples have revealed no significant changes in the crystalline texture or $c$-axis fabric of any of these sections. However, the bulk of the cores were stored in a separate facility near CRREI. at temperature settings from $-20^{\circ}$ to $-15^{\circ} \mathrm{C}$. In 1979 , during vertical sectioning of cores containing volcanic dust bands, it was noticed that the size of crystals in the ice appcared to have increased significantly over that observed in the original thin sections. 'T'his stimulated a more detailed rc-cxamination of additional corcs which revealed that sections of fine-grained, deformed ice from $1200-1800 \mathrm{~m}$ that originally exhibited very strong vertical $c$-axis fabrics had indeed undergone extensive recrystallization. In this paper, I wish to document in greater detail the nature and extent of recrystallization in the Byrd Station ice cores based on observations of thin sections made during the 25 years that have elapsed since the cores were drilled.

\section{OBSERVATIONS AND DISCUSSION}

Gow and Williamson (1976) characterized the structure of the $2164 \mathrm{~m}$ long cores from Byrd Station in terms of grain-size and $c$-axis-fabric changes. Grain-size was found to vary with depth according to the relationships demonstrated in Figure 1. Four principal zones of grain-size change were identified, each with its characteristic c-axis fabric. Representative fabrics for zones $\mathrm{A}, \mathrm{C}$ and $D$ are shown in Figure 1 . Re-examination of the original thin scctions, together with new sections of the parent samples stored at $-35^{\circ} \mathrm{C}$ at CRREL since 1968 , revealed no significant grain-size deviations from the profile shown in Figure 1. Photographs of the new thin sections prepared in 1993 are shown in Figure 2. Textures and fabrics are identical to those described by Gow and Williamson (1976). An example of ultra-fine-grained banding in ice containing volcanic dust from a zone $\mathbf{C}$ core is given in Figure 3. 'The fine-grained nature of this banding is attributed to the effect of volcanic particles inhibiting grain growth by grain-boundary pinning.

However, the great bulk of the cores from Byrd Station were stored in a separate facility. Vertical scctioning in 1979 of cores from the fine-grained ice in zone $\mathrm{C}$ showed that it had undergone extensive recrystallization, leading to the formation of a coarse-grained 


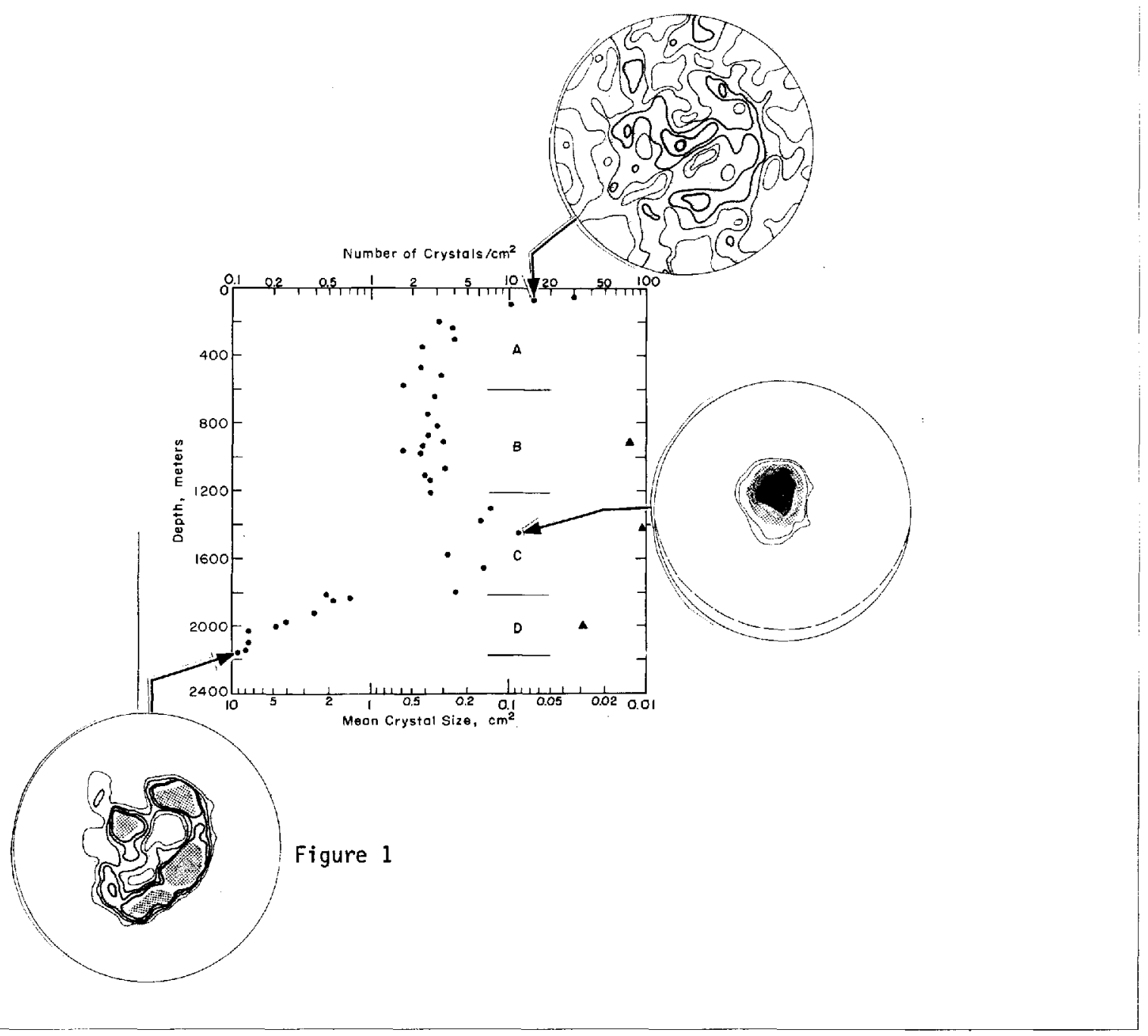

Fig. 1. Crystal size versus ice-core depth in the Antarctic ice sheet at Byrd Station. Triangles denote crystal size in ultrafine-grained ice in three volcanic dust bands. Zone A exhibits substantial grain growth with depth; zone $B$ is characterized by constant crystal size passing into zone $C$ consisting of ice of much smaller grain-size; zone $D$ defines the region of very rapid enlargement of crystals. These changes in cryslal size as a function of depth are also accompanied by major changes in the c-axis fabrics as indicated in the figure (after Gow and Williamson, 1976).

crystal structure that closely resembles, in texture and fabric, the naturally annealed ice from the bottom $350 \mathrm{~m}$ at Byrd Station. Representative examples of coarsegrained structure resulting from this recrystal-lization are illustrated in Figure 4. The magnitude of the crystalsize increase associated with this recrystallization is readily obscrved from a comparison with the textures shown in Figure 2. In addition to the change from a finegrained to a coarse-graincd texturc, a cursory examination of $c$-axis orientations of the recrystallized ice showed it now exhibited a much weaker fabric. Gores from zone C originally posscssed all the characteristics of highly deformed ice, including a granulated appearance of crystals, widespread occurrence of kink banding, undulatory extinction and strong single-pole $i$-axis fabrics, the type of structure that would be especially prone to annealing recrystallization at elevated temperatures. Note, that several of the examples of recrystallized ice in Figure 4 contain a fine-grained structure that can be identified with layers of volcanic dust. Apparently, even during recrystallization, the presence of abundant particles of volcanic dust is still capable of limiting the run-away crystal growth that has ovcrtaken the dust-poor matrix ice. It is of interest, in this regard, to note that Gow and Williamson (1976) reported a substantial preservation of fine-grained texture and vertical $c$-axis clustering in a dust layer enclosed in naturally annealed ice from $2006 \mathrm{~m}$ at Byrd Station. This naturally annealed ice exhibited a multi-pole fabric in place of the single vertical $c$-axis maximum. Annealing-type recrystallization during long-term storage of the Byrd Station cores appears to be restricted to the zone $\mathrm{C}$ ice. Complementary observations of thin sections of cores from above and below zone $\mathrm{C}$ ice show no signs of these ice cores having recrystallized, based on comparisons with original thin sections made in 1968.

A successful experiment to verify that the deformed, fine-grained strongly oriented ice of zone $\mathrm{C}$ readily recrystallizes into a coarse-grained structure with a greatly weakened fabric at elevated temperatures was reported by Gow and Sheehy (1987). In these experiments, a $5 \mathrm{~cm}$ long specimen of unrccrystallized core 


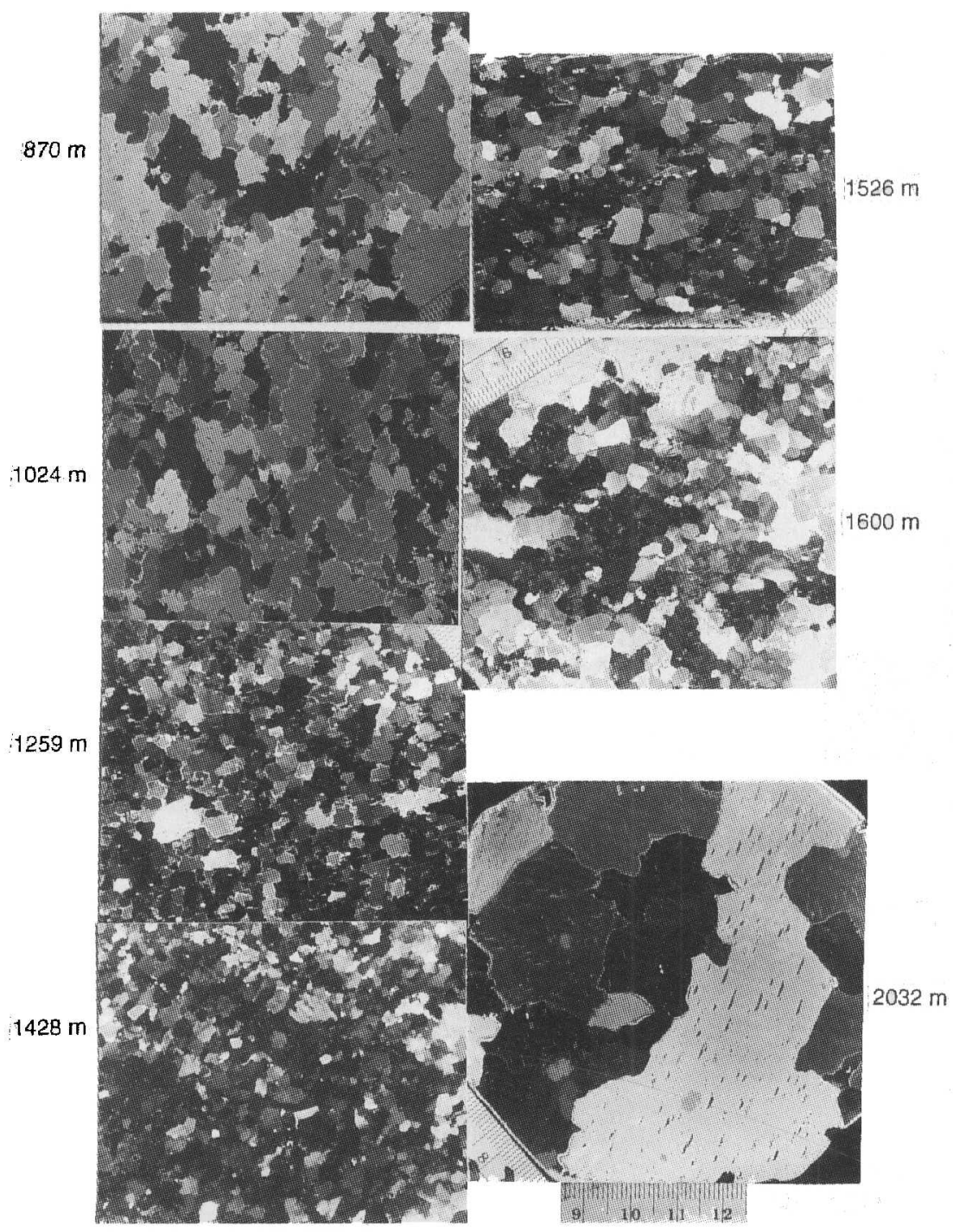

Fig. 2. Thin-section photographs of crystalline texture of ice from between 870 and $2032 \mathrm{~m}$ in decp cores from Byrd Station. These sections, prepared in 1993 from old samples stored at CRREL, show no change in texture or fabric from those prepared at the drill site in 1967-68; they still reflect the profile characteristics shown in Figure 1. The region of recrystallization discussed in the text of the paper is confined to zone C represented in Figure 2 by the originally fine-grained sections of ice from $1259,1428,1.526$ and $1600 \mathrm{~m}$, respectively. Smallest-scale sub-divisions measure $1 \mathrm{~mm}$. All sections, photographed between crossed polaroids, are at the same scale.

from $1800 \mathrm{~m}$ was hydrostatically compressed at $200 \mathrm{bar}$ for 1 month in a pressure chamber maintained at a temperature within a degree or so below the pressuremelting point $\left(-1.7^{\circ} \mathrm{C}\right.$ at 200 bar $)$. After removal from the pressure chamber, the specimen was sectioned and its structure compared with that of the original ice and of a specimen annealed at ambient pressure. Both the hydrostatically compressed ice and the sample testcd at ambient pressure werc found to have recrystallized into a condition that simulated in all aspects (see Fig. 5) the texture and fabric of naturally anncaled ice from the bottom $350 \mathrm{~m}$ at Byrd Station. These observations are also in accord with results of annealing obtained by Rigsby (1960) on a sample of highly deformed Greenland icc identical in texture and fabric to the $1800 \mathrm{~m}$ core piece from Byrd Station. Natural annealing of the deeper ice at Byrd Station begins as englacial temperatures rise above about $-14^{\circ} \mathrm{C}$ at $1800 \mathrm{~m}$ and ultimately reach the pressuremelting point at the bottom (2164 $\mathrm{m}$ depth).

The case can be made, on the basis of arguments presented above, that the recrystallization of the deformed ice in cores from zone $\mathrm{C}$ at Byrd Station occurred during some period of elevated tempcraturc, either during transshipment of the cores from Antarctica or while they were in storage in the United States. The latter situation seems more likely, based on examinations. of zone C core for cloudy-band abundance in 1970 (Gow and Williamson, 1971), at which time observations of grain-size-controled etch patterns on freshly cut surfaces of ice in zone $\mathrm{C}$ gave no indication of any drastic change in grain-size. From this, we conclude that recrystallization of zone C ice from between 1200 and $1800 \mathrm{~m}$ depth must have occurred sometime between 1970 and 1979 , when evidence of widespread recrystallization of zone $\mathrm{C}$ ice was first noted. The facility in which this recrystallization of the Byrd Station icc core occurred has sincc closed and no temperature records are available for the period the core was in storage. However, given that natural annealing of the Byrd Station core was first observed at englacial temperatures of about $-14^{\circ} \mathrm{C}$, it is 


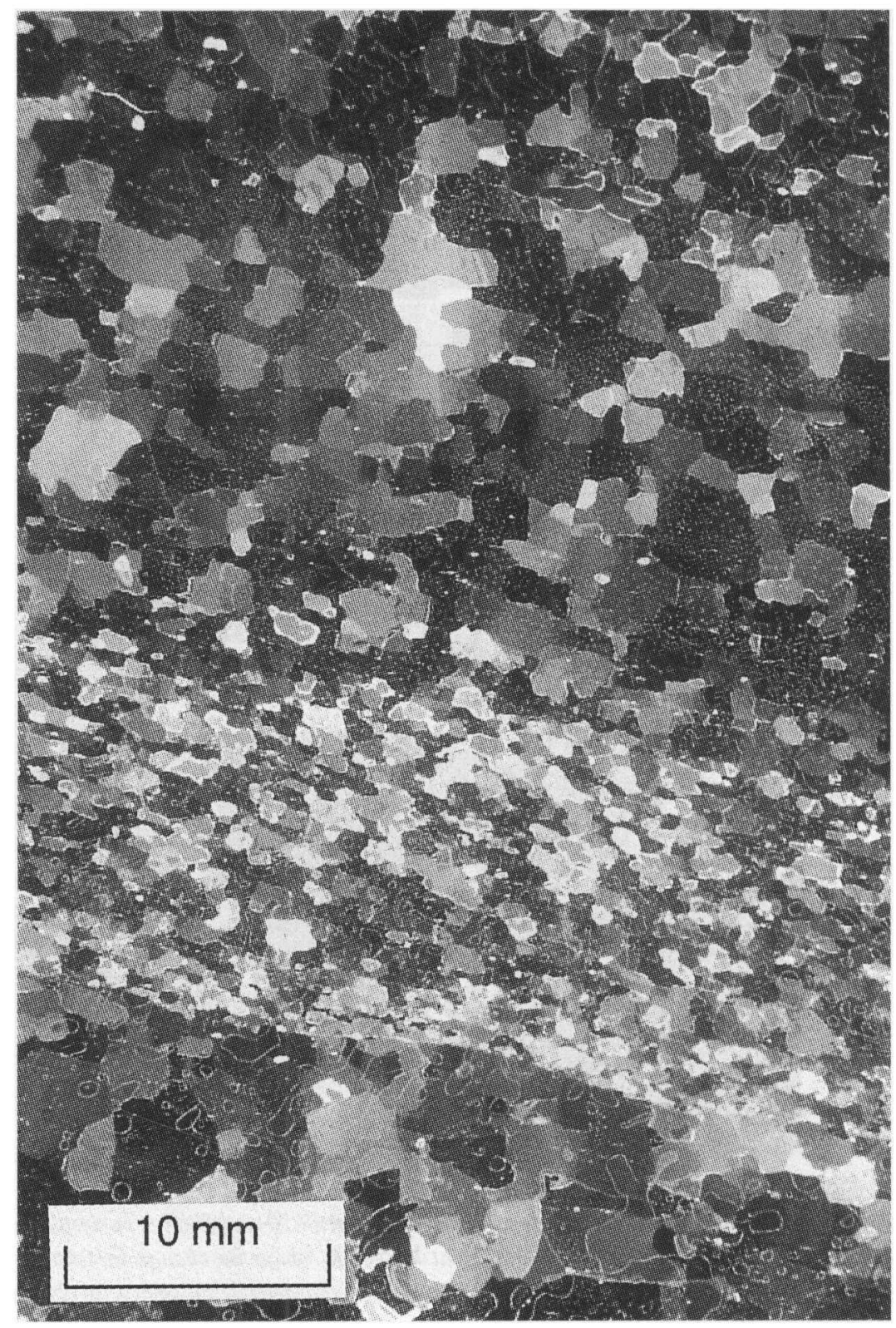

Fig. 3. Example of ultra-fine-grained crystat banding as it appears in a vertical thin section of normally fine-grained ice from $141.5 \mathrm{~m}$ in zone $\mathrm{C}$ at Byrd Station, photographed between crossed polaroids. The banded structure coincides with cloudy banding in the cores and is restricted to ice containing abundant particles of volcanic dust. The much-reduced size of crystals in the banded ice is attributed mainly to the effect of volcanic particles inhibiting grain growth through grain-boundary pinning. An estimated 2000 volcanic dust layers, occurring as cloudy bands up to $6 \mathrm{~cm}$ thick, were observed by Gore and Williamson (1971) in the Byrd Station core.

suggested here that annealing of the stored corcs began when temperatures in the storage facility rose above $-14^{\circ} \mathrm{C}$ for a sustained period. It should be emphasized that postdrilling recrystallization (annealing) of Byrd Station ice appears to be confined to deformed ice from zone C, since no signs of significant recrystallization have becn observed in corcs above or below zone $\mathrm{C}$.

\section{CONGLUSIONS}

Cores of deformed ice in the depth range of $12001800 \mathrm{~m}$ at Byrd Station have been found to have recrystallized while in storage in the United States. This recrystallization, which likcly was initiated when temperatures in the storage facility rose above about $-14^{\circ} \mathrm{C}$ for a sustained period of time, has resulted in grain-size enlargement and fabric weakening that simulatcs very closely the structurc of naturally annealed ice from the bottom $350 \mathrm{~m}$ at Byrd Station. These observations point up two areas of critical concern regarding the preservation of original crystal structure in polar ice cores: (1) the importance of preparing and photographing thin sections of freshly drilled core at the drill site to ensure accurate documentation of the original textures and fabrics, and (2) the need for cores to be transshipped and stored at temperatures of the order of $20 \mathrm{C}$ or colder to inhibit or minimize recrystallization. Temperatures during transshipment and storage should be constantly monitored to cnsure that temperatures are maintained at $20^{\circ} \mathrm{C}$ or colder at all 

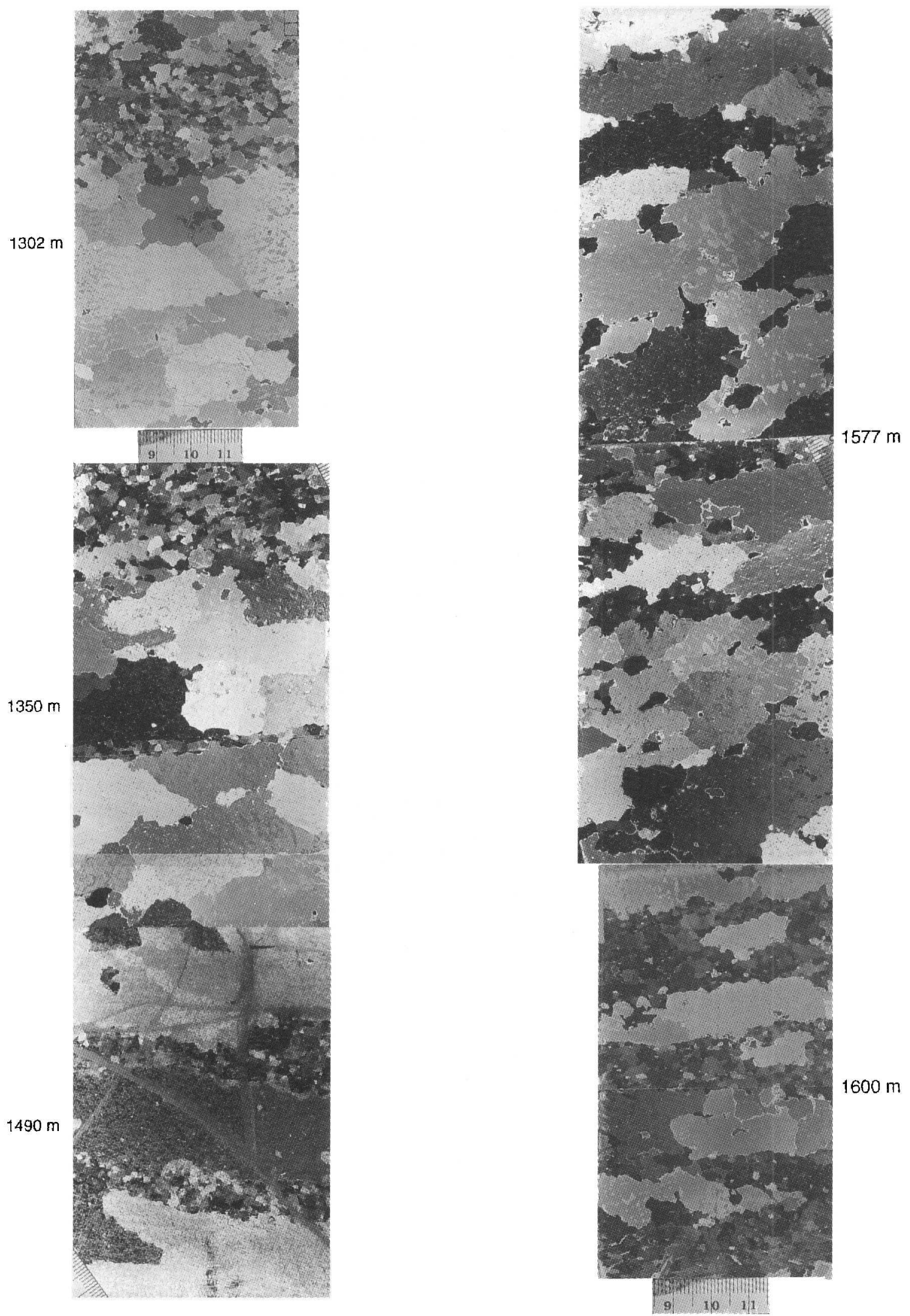

Fig. 4. Crossed-polaroid photographs of vertical thin sections of originally fine-grained ice from zone $C$ at Byrd Station, showing the extent to which the ice has undergone post-drilling recrystallization. A comparison with ice textures in Figure 2 shows the magnitude of the crystal-size changes imoloed. This recrystallization may have been initiated during transshipment of cores in 1969 from Antartica to the United States but is beliezed to have mainly occurred sometime during storage in the United States. Fine-grained layers in the 1302,1350,1490 and $1600 \mathrm{~m}$ sections all coincide with volcanic dust bands. Crystals in the dust bands may have undergone some increase in grain-size but the dust bands all appear to have relained their generally fine-grained character relative to the surrounding dust-poor ice. Vote that the size of recrystallized grains in dust-poor ice is comparable to that observed in naturally annealed ice at $2032 \mathrm{~m}$ in Figure 2. All sections were photographed between crossed polaroids at the same scale; smallest scale sub-division measures $1 \mathrm{~mm}$. 


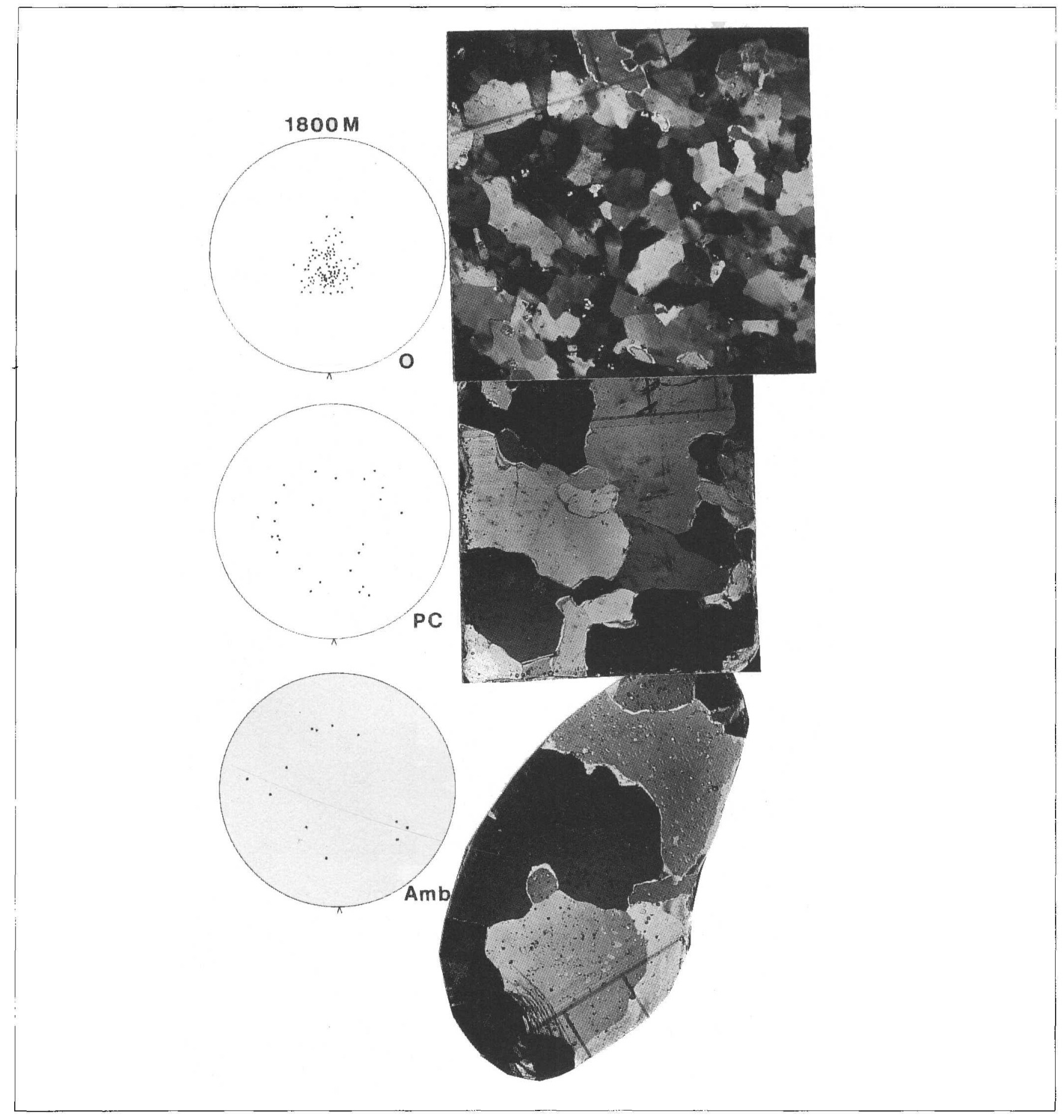

Fig. 5. Textures and c-axis fabrics of thin sections prepared from $5 \mathrm{~cm}$ long core samples from zone C, Byrd Station, prior to (0) and afler annealing near the pressure-melting point for 1 month at 200 bar in a pressure chamber (PC) and at ambient pressure (amb), respectively. All three sections were photographed between crossed polaroids. The grid scale measures $5 \mathrm{~mm}$ in all three sections (after Gow and Sheehy, 1987).

times. For researchers interested in the chemical and gas composition of the ice, recrystallization involving grainboundary sweeping and the redistrib-ution of impurities and entrapped gases could create problems of analysis and interpretation if the sampling interval is less than the mean dimensions of recrystallized grains.

\section{REFERENCES}

Gow, A.J. and W. Sheehy. 1987. Annealing recrystallization in laboratory and naturally deformed ice. 7. Phrs. Paris), 48, Collog. C1, 271-276. Supplément au 3.)

Gow, A.J. and T. Williamson. 1971. Volcanic ash in the Antarctic ice sheet and its possible climatic implications. Eorth Planet. Soi. Leth. 13 (1), 210-218.

Gow, A.J. and T. Williamson. 1976. Rheological implications of the internal structure and crystal fabrics of the West Antartic ice sheet as revaled by decp corc drilling at Byrd Station. CRREL Rep. 76-35.

Rigsby, G.P. 1960. Crystal orientation in a glacier and in experimentally deformed ice. 7. Glaciol., 3(27), 589-606.

The accuracy of references in the text and in this list is the responsibitity of the author, to whom queries should be addressed. 